\title{
Foetomaternal Haemorrhage (FMH): A Case for Routine Screening
}

\author{
Samuel S. Antwi-Baffour ${ }^{1, ~ *, ~ M a r t i n ~ A m e g a-Y e v u ~}{ }^{2}$, Ransford Kyeremeh ${ }^{1}$, Seidu A. Mahmood ${ }^{1}$, \\ Patrick F. Ayeh-Kumi ${ }^{1}$ \\ ${ }^{1}$ Department of Medical Laboratory Sciences, School of Allied Health Sciences, College of Health Sciences, University of Ghana, Korle- \\ $\mathrm{Bu}$, Accra, Ghana \\ ${ }^{2}$ Department of Medical Laboratory Services, Dangbe West District Hospital, Dangbe West District, Greater Accra Region, Ghana
}

\section{Email address:}

s.antwi-baffour@chs.edu.gh (S. S. Antwi-Baffour)

\section{To cite this article:}

Samuel S. Antwi-Baffour, Martin Amega-Yevu, Ransford Kyeremeh, Seidu A. Mahmood, Patrick F. Ayeh-Kumi. Foetomaternal Haemorrhage (FMH): A Case for Routine Screening. Journal of Gynecology and Obstetrics. Vol. 1, No. 3, 2013, pp. 11-15. doi: $10.11648 /$ j.jgo.20130103.11

\begin{abstract}
Background: Foetomaternal haemorrhage (FMH) over the years has been a matter of a major concern as it occurs asymptomatically and is one of the most common disorders responsible for foetal death. FMH occurs when there is leakage of foetal blood into maternal circulation due to breach in the physiological barrier between their circulations. In most pregnancies about $0.1 \mathrm{ml}$ foetal bleed occurs and it could be acute or chronic. The detection and quantification of any quantity of foetal red blood cells in maternal circulation would be important for obstetrical management of pregnant women. But FMH is not part of the routine screening done for pregnant women in many areas. Aims/objectives: The aim of this study was to assess the prevalence of FMH among pregnant women attending antenatal clinic in a District Hospital towards recommending the testing as part of the routine screening of pregnant women. Methods: A Kleihauer-Betke test (KBT) was used to quantify foetal red blood cells in venous blood from 212 expectant mothers recruited for the study. Thin blood smear (film) was prepared, dried, fixed, incubated in an acid solution and stained with eosin. They were then examined under the microscope. The foetal cells were counted and reported as a percentage of the adult cells and the FMH was calculated from that. Antibody screening was also done using the Coombs indirect test. Results: There was FMH prevalence rate of $0.5 \%$ when the cut-off of FMH was $30.0 \mathrm{ml}$. Also, $2 \%$ of the study group had antibodies in their serum. Conclusion: with the majority of the study population showing FMH below the level that could harm the foetus, it can be concluded that, the screening may not be mandatory but all at risk (rhesus negative) women should be screened routinely.
\end{abstract}

Keywords: Foetomaternal Haemorrhage, Kleihauer-Betke, Prevalence, Foetus

\section{Introduction}

Foetomaternal haemorrhage (FMH) results when foetal blood; especially red blood cells (RBCs) enter into maternal circulation due to loss of the normal physiological barrier between the foetal and maternal circulation as in reference [1]. The physiological barrier allows the blood of the expectant mother and that of the foetus to come into close contact without mixing. Foetal RBCs enters maternal circulation when pressure gradient occurs between the arterial foetal circulation and the venous maternal circulation as seen in reference [1-2]. During pregnancy, FMH could result from abdominal trauma, intra-uterine infection and placental distress causing vaginal bleeding or abdominal pain as in [2]. However, in many cases of FMH during pregnancy a direct cause cannot be found. FMH may also occur asymptomatically and is one of the most common and dangerous disorders responsible for foetal death as in reference [2-3].

Foetomaternal haemorrhage is known to occur in up to $70 \%$ of pregnancies but the amount of bleeding is less than $0.1 \mathrm{ml}$ in the majority of cases throughout gestation, though on rare occasions, FMH may be massive and fatal as in reference [4]. The detection and quantification of Foetal RBCs in maternal blood samples are important for the obstetrical management of pregnant women as in reference [5]. This is because, there are various complications associated with FMH such as immunization of the mother 
against foetal antigens and the formation of RBC antibodies leading to haemolytic disease of the new born (HDN), foetal hydrops, foetal intra-uterine death, hypovolaemic shock, neurologic injury and cerebral palsy as in reference [6-7].

Even though FMH present a serious risk to both mother and child, it can easily be overlooked or missed since it occur asymptomatically and currently not one of the routine screening tests for expectant mothers. It is therefore our view that knowledge of the prevalence of FMH in a society could be used as an indicator or otherwise for requesting FMH screening for at risk (rhesus negative) if not all pregnant women as part of their routine investigations.

\section{Materials and Methods}

This was a prospective study conducted from the month of June to July 2012.

\subsection{Study Population}

The study population was made up of two hundred and twelve (212) expectant women attending their first antenatal laboratory screening at the Dangbe West District Hospital, in the Greater Accra Region of Ghana. Their ages ranged from sixteen (16) to forty-four (44) years which were categorized into 15-19yrs; 20-24yrs; 25-29 yrs; 30 34yrs; 35-39yrs; and 40-44yrs. Negative control sample was taken from a male blood donor and positive from a cord blood that was mixed with a female sample.

\subsection{Ethical Consideration}

Ethical clearance for this research was sought from the Ethics and Protocol Review Committee at the School of Allied Health Sciences, University of Ghana, Legon. All the participants gave their informed consent before their samples were collected.

\subsection{Materials}

Some of the materials needed for the work include: Glass slides, coverslips, Pasteur pipettes, slide rack, light microscope, electrophoresis buffer, electrophoresis tank and power pack, filter paper, blotting paper, cellulose acetate membranes, fixative $(80 \%$ methanol), elution solution A: (7.5g/l of haematoxylin in $90 \%$ ethanol), elution Solution B: (24g of Ferric chloride, $20 \mathrm{ml}$ of $2.5 \mathrm{M} \mathrm{HCl}$ and $1 \mathrm{~L}$ double distilled water) and $0.25 \%$ aqueous eosin.

\subsection{Collection of Samples and Controls}

$2 \mathrm{ml}$ of venous blood was collected into Ethylenediamine tetra-acetic acid (EDTA) tubes from the 212 pregnant women. The blood samples were capped and numbered serially. Fresh EDTA blood was collected from an adult male volunteer as negative control while a mixture of fresh cord blood (one part) and adult female blood (100 parts) was collected in an EDTA tube as a positive control.

\subsection{Sample Processing and Examination}

The Kleihauer-Betke Test (KBT) was used for the detection and quantification of the foetal cells. The test has a principle that states that, Foetal haemoglobin $(\mathrm{HbF})$ is more resistant than adult haemoglobin $(\mathrm{HbA})$ to both acid elution and alkali denaturation. When dry blood films are fixed and then immersed in an acid buffer solution, $\mathrm{HbA}$ is denatured and eluted, leaving red cell ghosts. Red cells containing $\mathrm{HbF}$ are resistant and the haemoglobin can be stained; these Foetal cells stand out in a sea of ghost maternal cells.

Each venous blood sample was mixed well and a thin blood film (smear) was made and labeled with the patient's assigned ID number. The smears were quickly air-dried, fixed by dipping into $80 \%$ methanol for 5 minutes and allowed to dry. The fixed air-dried smears were rinsed rapidly in water and made to stand vertically on a slide rack to dry again. They were then arranged on a staining rack and flooded with the eluting solution (equal vol. of solution A and B) for 20 seconds. After, they were thoroughly but gently washed with water and stained for two (2) minutes with eosin. They were washed with water, air-dried and examined under the microscope.

\subsubsection{Examination - Detection/Screening}

The smears were screened under low power (x10 objective) and a minimum of 25 fields examined. If no foetal red cells were seen the FMH was reported as $<2.0 \mathrm{ml}$. If any foetal red cells were seen, a full quantification was performed as in reference [8-9].

\subsubsection{Examination - Quantification}

Slides with foetal red cells during screening were reexamined to estimate the number of foetal red cells present. An area of the film where the adult cells were not overlapping was selected for quantification under high power (x 40 objective). A minimum of six thousand (6000) adult cells were counted and the number of foetal cells noted. The foetal cells were expressed as a proportion of adult cells counted as in reference [8-9].

\subsection{Calculation of the FMH}

The formula for calculation assumes that the maternal red cell volume is $1800 \mathrm{ml}$, foetal cells are $22 \%$ larger than maternal cells and $92 \%$ of them stain darkly and are detected by the Kleihauer-Betke test on average. The foetal bleed was therefore calculated thus:

Uncorrected volume of bleed $=1800 \times$ foetal cells counted (F) / Adult cells counted (A).

Corrected for foetal volume $(1.22)=(1800 \times \mathrm{F} / \mathrm{A}) \times 1.22$ $=\mathrm{J}$, and Corrected for staining efficiency $(1.09)=\mathrm{J} \times 1.09$ $=$ foetal bleed as in reference [10].

\subsection{Hb-Electrophoresis}

Haemoglobin electrophoresis was performed on samples that showed sickling positive using cellulose acetate 
membrane at an alkaline $\mathrm{pH}(8.5)$ in order to detect those who have sickle cell anaemia and $S \beta^{+}$thalassemia as in reference [11].

\subsection{Anti-Body Screening}

The participants' sera were tested against commercial screening cells for clinically significant antibodies using an indirect antiglobulin method (Coombs test) as in reference [12].

\subsection{Data Analysis}

Statistical analysis was carried out with the 16th students' edition of the Statistical Package for Social Sciences (SPSS version 20.0) for Microsoft Windows. Frequency tables and Graphs were used for descriptive analysis.

\section{Result}

The study population was made up of 212 pregnant women who were between the ages of 16 to 44 years with the average age being 17 years. The age-groups of participants and their percentage representations were as follows: $15-19$ yrs (12.7\%), 20-24 yrs (26.4\%), 25-29 yrs (25.9\%), 30-34 yrs (21.2\%), 35-39 yrs (10.8\%) and 40-44 yrs (2.4\%) with one participant age unknown (0.5\%) (fig. 1$)$. Again out of the 212 participants, $77(36.3 \%)$ were in their first trimester, $86(40.6 \%)$ second trimester, $49(23.1 \%)$ in the third trimester (table 1).

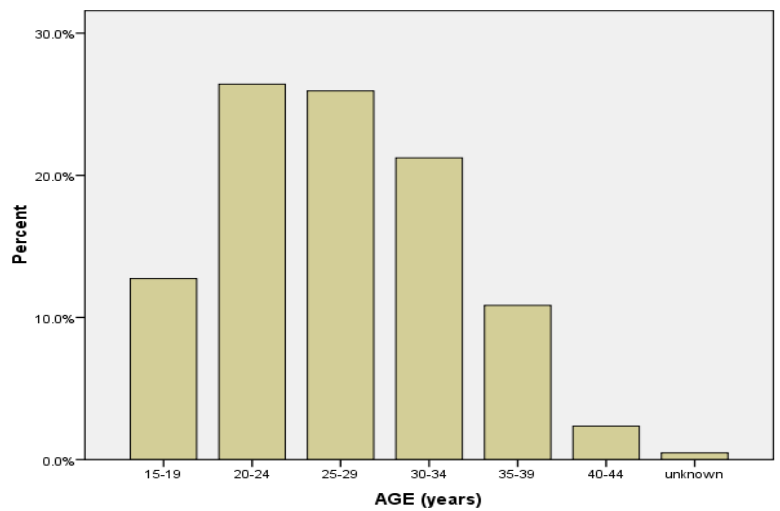

Fig 1. A graph showing the age groupings of the expectant mothers.

Table 1. A table representing the gestational period in trimesters (weeks) of participants.

\begin{tabular}{ccc}
\hline Gestation (trimester) & Number of participants & Percentage \\
\hline$\leq 13$ & 77 & 36.3 \\
$14-26$ & 86 & 40.6 \\
$27-40$ & 49 & 23.1 \\
\hline
\end{tabular}

The calculated foetomaternal haemorrhage volumes detected in the participants showed that out of the total number of 212 expectant mothers, those with $0.0-10.0 \mathrm{ml}$ of foetomaternal haemorrhage were $92.4 \% ; 10.1-20.0 \mathrm{ml}$ were $5.2 \%$; $20.1-30.0 \mathrm{ml}$ were $1.9 \%$; and $30.1 \mathrm{ml}$ and above were $0.5 \%$ respectively. Most of the expectant mothers $(99.5 \%)$ had normal FMH when the cut off was $30.0 \mathrm{ml}$ of FMH (table 2).

Table 2. Distribution of FMH among the age categories.

\begin{tabular}{ccc}
\hline FMH $(\mathbf{m l})$ & $\begin{array}{c}\text { Number of } \\
\text { Participants }\end{array}$ & Percentage \\
\hline $0.0-10.0$ & 196 & 92.4 \\
$10.1-20.0$ & 11 & 5.2 \\
$20.1-30.0$ & 4 & 1.9 \\
$>30.1$ & 1 & 0.5 \\
Total & $\mathbf{2 1 2}$ & $\mathbf{1 0 0}$ \\
\hline
\end{tabular}

The results of antibody screening done of the participants showed that only four (4) of them representing $2 \%$ were positive (fig. 2).

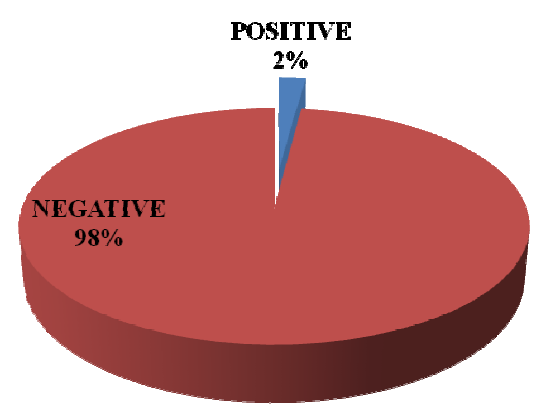

Fig 2. A pie chart showing results of antibody screening among the participants.

Sickle cell and genotype screening was done on all the participants to show any hemoglobin $(\mathrm{Hb}) \mathrm{F}$ detected was not as a result of the participants' sickling status. One hundred and eighty four (184) representing 87\% were sickling negative and $28(13 \%)$ were sickling positive. Out of the 28 who were sickling positive $27(12.7 \%)$ had haemoglobin AS and $1(0.47 \%)$ had haemoglobin SC (table 3).

Table 3. A table showing the results of Sickling, Hb genotype and Antibody screening.

\begin{tabular}{cccc}
\hline Variables & & Number of participants & Percentages \\
\hline \multirow{2}{*}{ Sickling } & Negative & 184 & 86.8 \\
& Positive & $28-$ AS (27); SC (1) & 13.2 \\
Antibody & Negative & 208 & 96 \\
screening & Positive & 4 & 4 \\
\hline
\end{tabular}

\section{Discussion}

A variety of strategies have evolved over the years in an attempt to diagnose FMH of high magnitude which is one of the complications of pregnancy as in reference [13]. These measures are aimed at preventing or reducing stillbirths, neonatal anaemia and foetal distress among others as in reference [13-14]. Although FMH of high magnitude could cause foetal mortality and morbidity, it is often overlooked in many areas of the world particularly in 
developing countries as in reference [15]. It is also a possible source of Alloimmunisation when there is $\mathrm{ABO}$ blood group or Rhesus D incompatibility between the expectant mothers and the foetuses. These antibodies especially anti-D cross the placenta and cause haemolysis of the foetus' RBCs leading to haemolytic disease of the new born (HDN). Most often the FMH are detected by clinical sign presentations which are nonspecific and are detected very late as in reference [16]. The purpose of this study was to determine the prevalence of FMH among pregnant women attending antenatal clinic in the Dangbe West District Hospital to make a case for routine screening of expectant mothers for FMH.

In this study, almost all the participants had some amount of foetal haemoglobin in their circulation. However, the calculated foetomaternal haemorrhage volumes put $99.5 \%$ of them in the normal range when the cut off for normal haemorrhaging was $30.0 \mathrm{ml}$ of FMH. The study therefore showed $0.5 \%$ prevalence of FMH that can have fatal consequence among the participants. This was relatively high compared to the prevalence rate of $0.3 \%$ reported by Sebring and colleagues in reference [4]. It was however significantly lower compared to a study carried out in Kenya in antenatal patients which had a prevalence rate of $32.2 \%$ as in reference [17]. These disparities may however be due to differences in study population size and area.

Since most individuals with haemoglobin SS tend to have appreciable amount of foetal haemoglobin in their blood circulation, sickling and haemoglobin genotype screening was performed on all the participants. The result (table 3) showed 27 participants to have haemoglobin AS and one person with SC. None of them had sickle cell disease (SS) or Sßeta thalassaemia. The antibody screening test on the other hand showed four (2\%) participants with antibodies in their serum. The detection of foetal haemoglobin in the participants could be attributed to foetal cells leaking into the maternal circulation as stipulated by Leavitt et al in reference [18] who indicated that a minimum of $0.5 \mathrm{ml}$ of foetal blood may pass transplacentally and could result in the isoimmunization of the expectant mother with subsequent immunological consequence.

\section{Conclusion}

Foetal-maternal haemorrhage (FMH) has been of considerable interest and importance to obstetricians for decades. Although small leaks are not implicated in intrauterine death, massive FMH (generally defined as 30.0 $\mathrm{ml}$ or more of foetal blood loss) is found in increased frequency in stillbirths and probably causes a significant number of these deaths. In fact, massive FMH may be the cause of around 1 in every 50 stillbirths. Causes of increased FMH are seen as a result of trauma, placental abruption or may be spontaneous with no cause found. For these reasons it is imperative that expectant mothers are accessed for FMH where possible. Standard Kleihauer-
Betke testing which is inexpensive and can be performed in any experienced laboratory is sufficient as in reference [8]. Tests which show $25 \%$ or more of estimated foetal blood volume lost should be viewed with serious concern. In these people with positive tests, follow-up testing should be done to rule out the possibility of a false positive because of a process (e.g. sickle cell trait) in the mother which may cause persistent elevation of foetal haemoglobin. With prevalence of $0.5 \%$, from our study, a case cannot be made for routine screening but the test would be recommended for at risk (rhesus negative) pregnant women with rhesus positive partners/foetuses. This will help avert serious and potentially fatal foetal or neonatal outcomes in many instances.

\section{References}

[1] Dziegiel M H, Nielsen L K and Berkowicz A. Detecting fetomaternal hemorrhage by flow cytometry. Curr Opin Hematol 2006; 13: 490-5.

[2] Dhanraj D, Lambers D. The incidences of positive Kleihauer-Betke test in low-risk pregnancies and maternal trauma patients. Am J Obstet Gynecol 2004; 190:1461.

[3] Dziegiel, M. H., Nielsen, L. K. \& Berkowicz, A. 2006. Detecting fetomaternal hemorrhage by flow cytometry. Curr Opin Hematol, 13, 490-5

[4] Sebring E and Polesky H. Foetomaternal haemorrhage: incidence, risk factors, time of occurrence, and clinical effects. Transfusion 1990; 30: 344-357.

[5] Rubod C, Deruelle P, Le Goueff F, Tunez V, Fournier M and Subtil D. Long-term prognosis for infants after massive Foetomaternal haemorrhage. Obstetric Gynecology 2007; 110: $256-260$.

[6] Salim R, Ben-Shlomo I, Nachum Z, et al. The incidence of large fetomaternal hemorrhage and the Kleihauer-Betke test. Obstet Gynecol 2005; 105:1039

[7] Adeniji AO, Mabayoje VO, Raji AA, et al. Feto - maternal haemorrhage in parturients: Incidence and its determinants. J Obstet Gynaecol 2008; 28:60.

[8] E Austin, S Bates, M de Silva, D Howarth, A Lubenko, M Rowley, M Scott, E Thomas, J White, M Williams. Guidelines for the Estimation of Fetomaternal Haemorrhage. Working Party of the British Committee for Standards inHaematology, Transfusion Taskforce 2008; Version 15: 123.

[9] Austin E, Bates S, De Silva M, Howarth D, Lubenko A, Rowley $M$ et al. Guidelines for the Estimation of Fetomaternal Haemorrhage, Working Party of the British Committee for Standards in Haematology, Transfusion Taskforce. 100 White Lion Street: British Society for Haematology. 2009.

[10] Mollison, P.L. (1972). Quantitation of transplacental haemorrhage. British Medical Journal, 3, 31-34.

[11] Dacie JV and Lewis SM. Practical Haematology. 8th ed. 2005. 
[12] AABB technical manual. 5th edition. AABB, 2005: 897 898.

[13] Bianchi DW, Romero R. Biological implications of bidirectional fetomaternal cell traffic: a summary of a National Institute of Child Health and Human Developmentsponsored conference. J Matern Fetal Neonatal Med 2003; 14:123.

[14] Rubod C, Houfflin V, Belot F, Ardiet E, Dufour P and Subtil D. Successful in utero treatment of chronic and massive fetomaternal hemorrhage with fetal hydrops. Fetal Diagn Ther 2006; 21: 410-413.

[15] David M, Smidt J, Chen FC, Stein U and Dudenhausen JW.
Risk Factors For Fetal To-Maternal Transfusion In Rh DNegative Women--Results Of A Prospective Study On 942 Pregnant Women. J Perinat Med 2004; 32: 254-7.

[16] Augustson B M, Fong EA, Grey D E, Davies JI and Erber WN. Postpartum anti-D: can we safely reduce the dose? Med J Aust 2006; 184: 611-3.

[17] Kizza A and Rogo K. Feto-maternal haemorrhage in Kenya. East African Medical Journal 1990; 67(11): 801-807.

[18] Leavitt BG, Huff DL, Bell LA and Thurnau GR. Placental Drainage Of Fetal Blood At Cesarean Delivery And Feto Maternal Transfusion; A Randomized Controlled Trial. Obstet Gynecol 2007; 110: 608-611. 